\title{
PELATIHAN HSK SEBAGAI UPAYA MENINGKATKAN KEMAHIRAN BERBAHASA MANDARIN BAGI GURU-GURU BAHASA MANDARIN SE-MALANG RAYA
}

\author{
Karina Fefi Laksana Sakti ${ }^{11}$ \\ 1)Jurusan Sastra Jerman, Program Studi Pendidikan Bahasa Mandarin, Fakultas sastra, Universitas Negeri Malang, \\ Malang, Jawa Timur, Indonesia \\ Corresponding author : Karina Fefi Laksana Sakti \\ E-mail : karryna.sakti.fs@um.ac.id
}

Diterima 25 November 2021, Disetujui 04 Desember 2021

\begin{abstract}
ABSTRAK
Pembelajaran Bahasa Mandarin menjadi kebutuhan masyarakat untuk membekali diri dalam dunia kerja, sehingga banyak sekolah mulai dari Sekolah Dasar (SD) sampai Sekolah Menengah Atas (SMA) memunculkan mata pelajaran Bahasa Mandarin. Guru merupakan salah satu faktor utama berlangsungnya pembelajaran efektif. sebagian besar guru Bahasa Mandarin di Malang belum memiliki sertifikat 汉语水平考试 HSK yang menjadi tolak ukur kemampuan minimal seseorang dalam menguasai Bahasa Mandarin, terutama bagi pengajar atau guru Bahasa Madarin. Pengabdian pelatihan 汉语水平 考试 HSK sebagai upaya meningkatkan kemahiran berbahasa Mandarin bagi guru-guru bahasa Mandarin ini dimaksudkan untuk mengoptimalkan tingkat profesionalitas serta kemampuan berbahasa Mandarin guru-guru Bahasa Mandarin. Adapun kegiatan dalam pengabdian berupa (1) Memperkenalkan beberapa hal yang harus diperhatikan dalam 汉语水平考试 HSK; (2) Meperkenalan materi 汉语水平考试 HSK; (3) Mendemonstrasikan penggunaan kosakata, tata Bahasa serta tips-tips mengertakan tes 汉语水平考试 HSK; (4) Guru praktek mengerjakan secara langsung tes 汉语水平考试 HSK 4. Hasil dari kegiatan pelatihan HSK ini menunjukkan bahwa para guru antusias dalam mengikuti pelatihan yang dilaksanakan, terbukti dari para guru dengan antusias mengerjakan soal latihan HSK, mengajukan beberapa pertanyaan mengenai HSK serta merespon pemateri selama kegiatan pelatihan HSK berlangsung. Dengan demikian, dapat disimpulkan bahwa pelatihan HSK penting dilakukan untuk meningkatkan kemampuan berbahasa Mandarin guru-guru bahasa Mandarin dan juga dapat menambah wawasan tentang HSK terbaru bagi guru.
\end{abstract}

Kata kunci: pelatihan; HSK; bahasa mandarin

\begin{abstract}
Learning Chinese has become a community need to equip themselves in the world of work so that many schools from Elementary School (SD) to Senior High School (SMA) introduce Chinese subjects. The teacher is one of the main factors for effective learning to take place. Most Chinese teachers in Malang do not yet have an HSK certificate which is a benchmark for a person's minimum ability to master Chinese, especially for Chinese teacher. The HSK training as an effort to improve Chinese language proficiency for Chinese teachers is intended to optimize the level of professionalism and Chinese language skills of Chinese teachers. The activities in this training are (1) Introducing several things that must be considered in HSK; (2) Introducing the material 汉语水平考试 HSK; (3) Demonstrating the use of vocabulary, grammar, and tips for writing the HSK test; (4) Teachers practice working directly on the HSK test level 4. The results of this HSK training activity show that the teachers are enthusiastic in participating in the HSK test the training carried out, the teachers enthusiastically working on the HSK training, asking several questions about HSK, and responding to the presenters during the HSK training activities. Thus, it can be concluded that HSK training is important to improve the Mandarin language skills of Chinese teachers and can also add insight into the latest HSK for teachers.
\end{abstract}

Keywords: training; HSK; chinese language.

\section{PENDAHULUAN}

Kebutuhan guru Bahasa Mandarin di Indonesia semakin lama semakin bertambah dikarenakan bahasa Mandarin menjadi salah satu bahasa terpenting di dunia, sekaligus menjadi Bahasa resmi Perserikatan BangsaBangsa (PBB). Sebagaimana yang diungkapkan oleh (Xuming, 2013) bahasa 
Mandarin merupakan Bahasa yang paling banyak digunakan di dunia, dan telah menjadi Bahasa resmi PBB. Dengan berkembang pesatnya Bahasa Mandarin di dunia menjadikan ketertarikan masyarakat terhadap pembelajaran bahasa dan budaya Tiongkok semakin meningkat, termasuk masyarakat Indonesia. Saat ini, pembelajaran Bahasa Mandarin menjadi kebutuhan masyarakat untuk membekali diri dalam dunia kerja, sehingga banyak sekolah mulai dari Sekolah Dasar (SD) sampai Sekolah Menengah Atas (SMA) memunculkan mata pelajaran Bahasa Mandarin.

Guru merupakan salah satu faktor utama berlangsungnya pembelajaran efektif. Tugas utama guru adalah mengupayakan penguasaan materi pembelajaran, termasuk juga guru Bahasa Mandarin. (Haidir, 2014) menjelaskan bahwa pendidik atau guru yang efektif adalah pendidik atau guru yang menguasai materi pembelajaran serta keterampilan mengajar yang baik. Salah satu tugas guru adalah menyusun materi yang selanjutnya dapat digunakan sebagai bahan ajar atau acuan dalam mengajar Bahasa Mandarin, terutama pengajaran Bahasa Mandarin di Indonesia yang masih sangat terbatas ketersediaan bahan ajar Bahasa Mandarin. Dengan kemampuan guru yang menguasai materi Bahasa Mandarin dengan baik, guru dapat menyusun materi ajar yang tepat dan sesuai dengan kurikulum serta kebutuhan siswa pada jenjan sekolah tertentu.

Tidak bisa dipungkiri sebagian besar guru Bahasa Mandarin di Indonesia adalah lulusan Prodi Bahasa Mandarin atau bahkan bukan lulusan Bahasa Mandarin melainkan hanya mengikuti kursus Bahasa Mandarin yang tidak atau belum memiliki sertifikat 汉语水平考试 HSK 4. (Sumei, 2012) menjelaskan bahwa 汉语水平考试 HSK Ini adalah tes kemampuan bahasa Mandarin berstandar internasional yang diluncurkan oleh lembaga pemerintah Tiongkok, yang berfokus pada kemampuan peserta untuk berkomunikasi dalam bahasa Mandarin dalam kehidupan sehari-hari, belajar, dan bekerja. Saat ini, semakin banyak pembelajar Bahasa Mandarin yang mengikuti tes HSK untuk mendapatkan sertifikat HSK sebagai tolak ukur bahwa mereka menguasai Bahasa Mandarin dengan baik. Sebagaimana yang dijelaskan oleh (Liping, 2013) bahwa sejalan dengan berkembangnya pembelajaran bahasa Mandarin, tes HSK semakin banyak diikuti oleh pembelajar asing. Selama penulis mengamati pembelajaran bahasa Mandarin di Indonesia tepatnya di kota Malang, penulis menemukan bahwa sebagian besar guru Bahasa Mandarin di Malang belum memiliki sertifikat 汉语水平考试 HSK 4 yang menjadi tolak ukur kemampuan minimal seseorang dalam menguasai Bahasa Mandarin, terutama bagi pengajar atau guru Bahasa Madarin. (Fatimah, 2016) menjelaskan bahwa level HSK 4 adalah harus menguasai kurang lebih 1200 kosakata bahasa Mandarin.

Dalam pengajaran bahasa Mandarin oleh guru-guru SMA diperlukan penguasaan bahasa Mandarin yang mumpuni, agar pengajar atau guru dapat mentrasfer ilmu bahasa Mandarin kepada siswa dengan baik. Penguasaan materi yang setara dengan 汉语水 平考试 HSK 4 dimaksudkan untuk mengoptimalkan tingkat profesionalitas serta kemampuan penguasaan materi Bahasa Mandarin oleh guru-guru Bahasa Mandarin.

Dari analisis tersebut perlu dilakukan langkah yang signifikansi dengan tujuan para guru nantinya akan mempunyai kemampuan mengikuti tes 汉语水平考试 HSK 4, yang nantinya jika lolos tes tersebut, guru akan mendapat sertifikat 汉语水平考试 HSK 4 yang dikeluarkan langsung oleh lembaga pemerintahan Tiongkok. Adapun langkah langkah dalam mengatasi permasalahan yang dialami oleh guru-guru SMA di kota Malang adalah yang paling awal dengan cara melakukan studi pendahuluan untuk mengetahui permasalahan yang ada dilapangan secara tepat memberikan pemahaman bahwa mengikuti tes 汉语水平考 试 HSK 4 sangatlah penting, memberikan pemahaman bahwa kemampuan setara dengan 汉语水平考试 HSK 4 merupakan tolak ukur minimal yang harus dikuasai oleh guru Bahasa Mandarin. Selain itu, kemampuan setara dengan 汉语水平考试 HSK mempunyai peranan yang sangat penting guna meningakatkan profesionalitas guru Bahasa Mandarin

\section{METODE}

Metode pelaksanaan yang digunakan dalam pelatihan 汉语水平考试 HSK 4 sebagai upaya meningkatkan kemahiran berbahasa berbahasa Mandarin bagi guru-guru bahasa Mandarin se-Malang Raya yaitu metode pembimbingan. Guru-guru bahasa Mandarin se-Malang Raya dibimbing untuk menguasai materi yang setara dengan 汉语水平考试 HSK 4.

\section{Pengarahan}

Pada tahap awal, guru-guru diberikan pengarahan tentang pentignya dan manfaat 
lulus tes HSK 4 dalam pengajaran bahasa Mandarin.

a. Meperkenalan kosa kata dan tata Bahasa yang harus dikuasai sebelum menginjak ke tahapan penjelasan materi, guru akan diberikan penjelasan secara detail mengenai tips-tips dalam mengerjakan soal tes HSK 4. Tips-tips tersebut terstruktur mulai dari tips atau langkah mengerjakan soal menyimak, membaca, dan menulis pada tes HSK 4.

b. Menjelaskan materi HSK 4. Pada tahap ini pemateri menjelaskan mengenai penggunaan kosakata dan tata Bahasa dalam HSK 4 secara langsung kepada guru guru bahasa Mandarin. Guru guru diwajibkan memperhatikan penjelasan materi HSK 4, sehingga nanti nya guru-guru akan memahami langkah mengerjakan tes HSK 4.

2. Praktek mengerjakan tes HSK 4

a. Guru mempraktekan secara langsung. Setelah guru memahami langkah mengerjakan soal tes HSK 4, guru-guru di perkenankan untuk mencoba mengerjakan soal tes HSK 4 secara mandiri.

\section{HASIL DAN PEMBAHASAN}

Hasil yang dicapai melalui kegiatan pengabdian ini dituangkan dalam bentuk hasil kegiatan pada setiap tahap pelaksanaan sebagai berikut.

\section{Perencanaan Kegiatan}

Pelaksanaan pelatihan media yang dilakukan pada tahap perencanaan adalah sebagai berikut.

(a) Mengkomunikasikan kepada guru Bahasa Mandarin di sekolah-sekolah yang menjadi mitra pelatihan HSK 4 汉语 水平考试四级. Pada tahap ini, tim pelaksana pelatihan menghubungi ketua MGMP Bahasa Mandarin kota Malang untuk berkoordinasi membahas kelanjutan kegiatan pelatihan.

(b) Menyosialisasikan kegiatan pelatihan HSK 4 汉语水平考试四级 kepada guruguru Bahasa Mandarin se-kota Malang. Sosialisasi dilaksanakan secara daring menggunakan media zoom. Setelah tahap sosialisasi, tim pelaksana menyebarkan angket untuk menjaring informasi ketersediaan guru-guru Bahasa Mandarin sekota Malang mengikuti pelatihan HSK 4 汉语水平考 试四级 serta permasalahan yang dihadapi pada saat proses pembelajaran khususnya pada masa pandemi saat ini.

(c) Tim menentukan materi untuk disampaikan saat pelatihan serta soalsoal yang akan diujicobakan.

\section{Pelaksanaan Tindakan}

Tindakan dalam kegiatan pengabdian ini berupa implementasi Program yang dilakukan secara virtual melalui aplikasi zoom pada tanggal 14 Agustus 2021. Kegiatan-kegiatan yang dilakukan dalam implementasi program adalah sebagai berikut.

(a) Meperkenalan level HSK

Sebelum menuju ke tahapan penyampaian materi, guru akan diberikan penjelasan secara detail mengenai pentingnya HSK terutama HSK 4 汉语水平考试四级. Penjelasan tentang HSK dibutuhkan agar guru-guru Bahasa Mandarin menyadari pentingnya menguasai materi setara HSK 4. Penjelasan ini dilakukan dengan durasi 10 menit.

(b) Menjelaskan jenis soal tes HSK 4

Pada tahap ini pemateri menjelaskan mengenai jenis-jenis soal tes yang terdapat pada HSK 4 汉语水平考试四. Penjelasan jenisjenis soal HSK 4 ditujukan agar guru-guru Bahasa Mandarin memahami jumlah jenis soal, dan jumlah seluruh soal, serta bobot penilaian setiap jenis soal. Pada tahap ini kegiatan narasumber memberikan bimbingan dan pelatihan terkait dengan cara mengerjakan masing-masing jenis soal tes HSK 4 汉语水平 考试四级 kepada guru-guru Bahasa Mandarin se-kota Malang.

(c) Tahap praktek mengerjakan soal tes HSK.

Pada tahap ini guru-guru Bahasa Mandarin mencoba mengerjakan soal tes HSK 4 dengan arahan narasumber. Praktek mengerjakan soal HSK 4 ini dilakukan dengan alokasi waktu 45 menit.

(d) Sesi Tanya jawab.

Pada tahap ini peserta pelatihan diberikan kesempatan untuk bertanya mengenai kendala-kendala yang dihadapi dalam mengerjakan tiap jenis soal HSK 4 serta berbagi pengalaman tentang kendala yang dihadapi selama proses pembelajaran Bahasa Mandarin di sekolah.

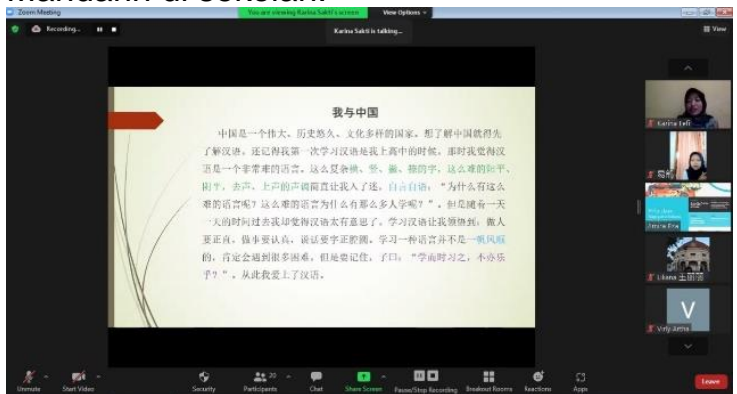

Gambar 1. Dokumentasi pelatihan secara daring 1 


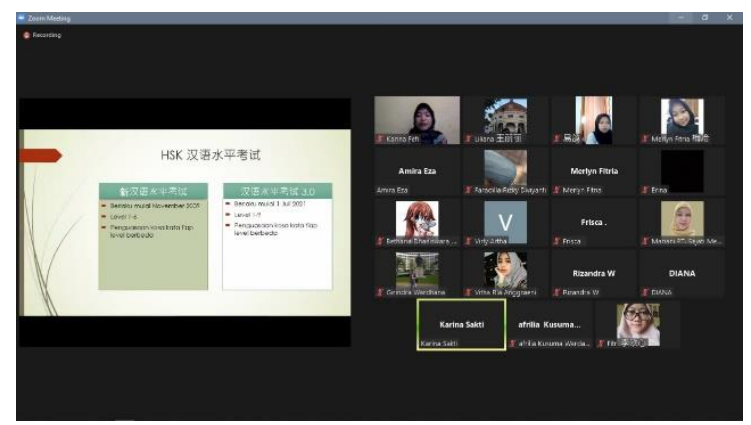

Gambar 2. Dokumentasi pelatihan secara daring 2

\section{SIMPULAN DAN SARAN}

Berdasarkan uraian di atas didapatkan kesimpulan bahwa pelatihan HSK penting dilakukan untuk meningkatkan kemampuan berbahasa Mandarin guru-guru Bahasa Mandarin di SMA sekaligus menambah wawasan tentang HSK 3.0. Dari hasil pelatihan terlihat para guru Bahasa Mandarin sangat antusias dalam mengikuti kegiatan pelatihan HSK, terbukti dari para guru dengan antusias mengerjakan soal latihan HSK, mengajukan beberapa pertanyaan mengenai HSK serta merespon pemateri selama kegiatan pelatihan HSK berlangsung. Dengan demikian, dapat disimpulkan bahwa pelatihan HSK penting dilakukan untuk meningkatkan kemampuan berbahasa Mandarin guru-guru bahasa Mandarin dan juga dapat menambah wawasan tentang HSK terbaru bagi guru. Melalui pelatihan HSK ini diharapkan terjadinya jalinan komunikasi yang lebih baik antar guru Bahasa Mandarin, sehingga jika nantinya terdapat pelatihan-pelatihan lanjutan mengenai Bahasa Mandarin dapat kembali melibatkan guru-guru Bahasa Mandarin di SMA se-Malang Raya. Hal tersebut dilakukan untuk membantu mengatasi kendala-kendala yang dihadapi dalam melakukan pembelajaran Bahasa Mandarin selain materi HSK. Selanjutnya, agar pemahaman tentang HSK dan kemampuan mengerjakan soal HSK dapat ditingkatkan, peserta pelatihan diharapkan juga harus terus berlatih meningkatkan penguasaan materi HSK.

\section{UCAPAN TERIMAKASIH}

Pengabdian ini didanai oleh Hibah Penerimaan Negara Bukan Pajak (PNBP) Fakultas Sastra Universitas Negeri Malang. saya berterima kasih kepada asisten peneliti atas upaya luar biasa mereka dalam membantu proyek ini dalam pengumpulan data dan transkripsi data. Selain itu, saya berterima kasih kepada keluarga, siswa, staf sekolah, dan kolega atas partisipasi dan dukungannya dalam membantu pengabdian ini.

\section{DAFTAR RUJUKAN}

Amanah, Siti dkk. (2016). Pemberdayaan Sosial Petani-Nelayan, Keunikan Agroekosistem, dan Daya Saing. Jakarta: Yayasan Pustaka Obor Indonesia.

Fatimah, B. M. O. (2016). Analisis Kesalahan Mengerjakan Hsk 3 Pada Kemampuan Menulis Mahasiswa Angkatan 2013 Prodi Pendidikan Bahasa Mandarin Universitas Negeri Semarang. Universitas Negeri Semarang.

Gintings, Abdorrakhman.(2011). Manajemen Pendidikan Dan Pelatihan: Esensi Praktis. Bandung: Humaniora,

Haidir, dan S. (2014). Strategi Pembelajaran (Suatu Pendekatan Bagaimana Meningkatkan Kegiatan Belajar Siswa Secara Transformatif). Medan: Perdana Publishing.

Liping, J. (2013). Standard Course 标准教程 HSK 6 上. Beijing: Beijing Language and Culture University Press.

Lokajaya, Devi Natalia Harijanto. (2019). Meningkatkan Literasi Visual Dan Kepekaan Fonologi Dalam Belajar Karakter Mandarin Piktograf Melalui Pengajaran Visual Pada Siswa K3A Di Sekolah Pelita. Masters thesis, Universitas Pelita Harapan.

Putri, Manda Prima Winarti, dkk. (2018). Analisis Kesulitan Mahasiswa Semester Vi Angkatan 2013 Prodi Pendidikan Bahasa Mandarin Universitas Negeri Semarang Dalam Memahami Teks 阅读 pada 汉语水平考 试 ( HSK ) Level IV. Journal of Chinese Learning and Teaching. http://journal.unnes.ac.id/nju/index.php /longdaxiaokan.

Sumei, W. (2012). 新汉语水平考试模拟试题集. Beijing Language and Culture University Press 北京语言大学出版.

Thamrin, Lily. dkk. (2021). Sosialisasi Pembelajaran Bahasa Mandarin Di Sma/Ma Raudhatul Ulum Meranti Kuburaya. Jurnal Masyarakat Mandiri vol 5, no 1. DOI: https://doi.org/10.31764/jmm.v5i1.3234

Xuming, N. (2013). 中国概况 China Overview. Beijing Language and Culture University Press 北京语言大学出版. 